\title{
GROWTH, COGNITIVE AND ACADEMIC OUTCOMES AT 8 YEARS IN CHILDREN BORN EXTREMELY PRETERM OVER THREE ERAS
}

the women's

the royal womenis hospita victoria australia $\underline{\text { LM Hickey }}{ }^{1,2,3}$, JYL Cheong 2,3,4, LW Doyle 2,3,4,5, for the Victorian Infant Collaborative Study Group.

${ }^{1}$ Department of Neonatal Medicine, The Royal Children's Hospital; ${ }^{2}$ Clinical Sciences, Murdoch Children's Research Institute ${ }^{3}$ Department of Paediatrics, University of Melbourne; ${ }^{4}$ Neonatal Services, Royal Women's Hospital;

${ }^{5}$ Department of Obstetrics \& Gynaecology, University of Melbourne; all based in Melbourne, Australia.

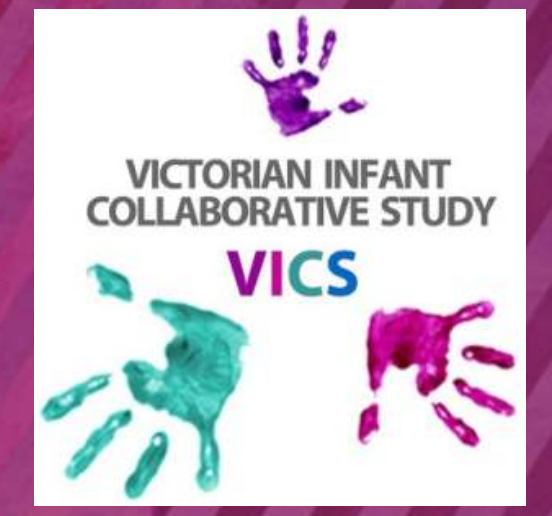

\section{BACKGROUND}

Survival rates are improving for infants born extremely preterm (EP; 22 - 27 completed weeks of gestation)

However, rates of adverse neurosensory, motor, cognitive and respiratory outcomes are increasing

Poor growth is associated with impaired neurodevelopment up to 2 years of age but impairment in early childhood is not a strong predictor of later function

- Anthropometric measurements from birth to 8 years and associations with cognitive and academic outcomes across three eras in EP children have not been reported previously

\section{OBJECTIVES}

1) To compare anthropometric measurements at set time points from birth to 8 years in surviving children who were born extremely preterm over three different eras

2) To investigate associations between these measurements and cognitive and academic outcomes in mid-childhood

\section{METHODS}

Design: prospective observational cohort studies.

Setting: The state of Victoria, Australia.

Participants: all EP live births in the state of Victoria, free of lethal anomalies, were recruited from three distinct eras, i.e. 1991-92 (24 months), 1997 (12 months) and 2005 (12 months).

Data collection: relevant sociodemographic, perinatal and neonatal data were collected for mothers and their infants.

Assessments: surviving EP children were;

1) measured for weight, height and head circumference at different time points between birth and 8 years corrected for prematurity

2) tested for cognitive ability (Weschler Intelligence Scales for Children or Differential Ability Scales) and academic performance (Wide Range Achievement Tests) at 8 years

Data Analysis: performed using STATA v15.1. Comparisons of growth measurements over time were calculated using mixed models and associations between growth and IQ, reading, spelling and mathematics scores at 8 years were tested using linear regression.

\section{RESULTS}

\section{Table 1 Participant characteristics contrasted between eras}

\begin{tabular}{|l|c|c|c|}
\hline Perinatal variables & 1991 - 92 & 1997 & $\mathbf{2 0 0 5}$ \\
\hline Fully assessed at 8 years, $\mathbf{n}$ (\% of live born survivors) & $\mathbf{2 1 0 ~ ( 9 3 \% )}$ & $\mathbf{1 4 2}(\mathbf{9 4 \% )}$ & $\mathbf{1 4 7}(\mathbf{8 6 \% )}$ \\
Antenatal corticosteroids, $\mathrm{n}(\%)$ & $149(71)$ & $126(89)$ & $125(85)$ \\
Multiple birth, $\mathrm{n}(\%)$ & $69(33)$ & $29(20)$ & $35(24)$ \\
Gestational age at birth, wks, mean (SD) & $25.8(1.1)$ & $25.6(1.2)$ & $25.8(1.2)$ \\
Birth weight, g, mean (SD) & $887(175)$ & $820(173)$ & $867(193)$ \\
Male, $\mathrm{n}(\%)$ & $104(50)$ & $79(56)$ & $72(49)$ \\
Exogenous surfactant, $\mathrm{n}(\%)$ & $88(42)$ & $120(85)$ & $127(86)$ \\
Patent ductus arteriosus, $\mathrm{n}(\%)$ & $126(60)$ & $75(53)$ & $113(77)$ \\
Grade 3 or 4 intraventricular haemorrhage, $\mathrm{n}(\%)$ & $17(8)$ & $5(4)$ & $13(9)$ \\
Cystic periventricular leukomalacia, $\mathrm{n}(\%)$ & $14(7)$ & $5(4)$ & $5(3)$ \\
Necrotising enterocolitis, $\mathrm{n}(\%)$ & $15(7)$ & $8(6)$ & $16(11)$ \\
Postnatal corticosteroids, $\mathrm{n}(\%)$ & $85(40)$ & $65(46)$ & $32(22)$ \\
Bronchopulmonary dysplasia & $98(47)$ & $59(42)$ & $46(31)$ \\
\hline
\end{tabular}

Anthropometric measurements

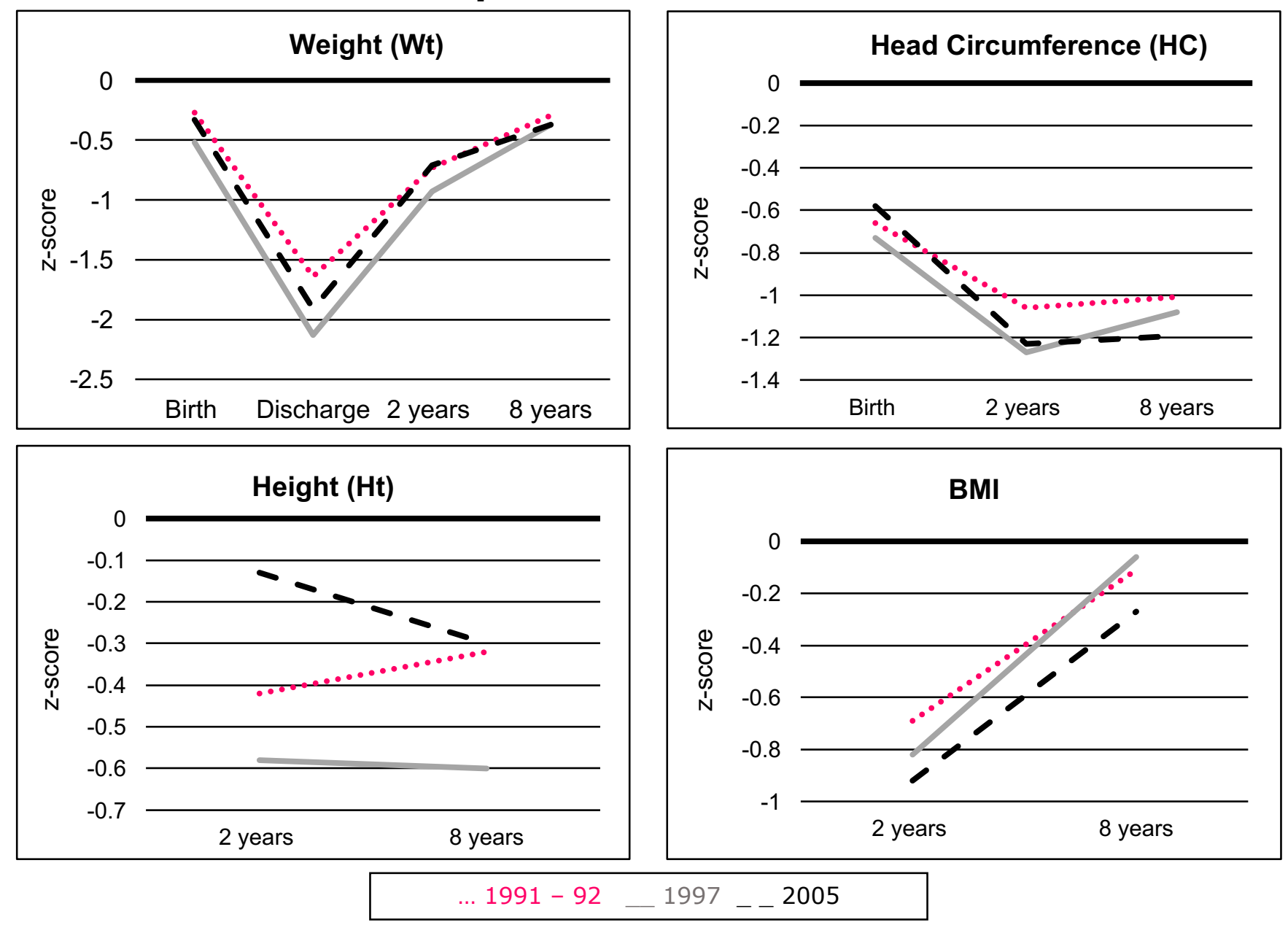

Figure 1 Mean z-scores at each time point across eras
Growth and Cognitive and Academic Outcomes
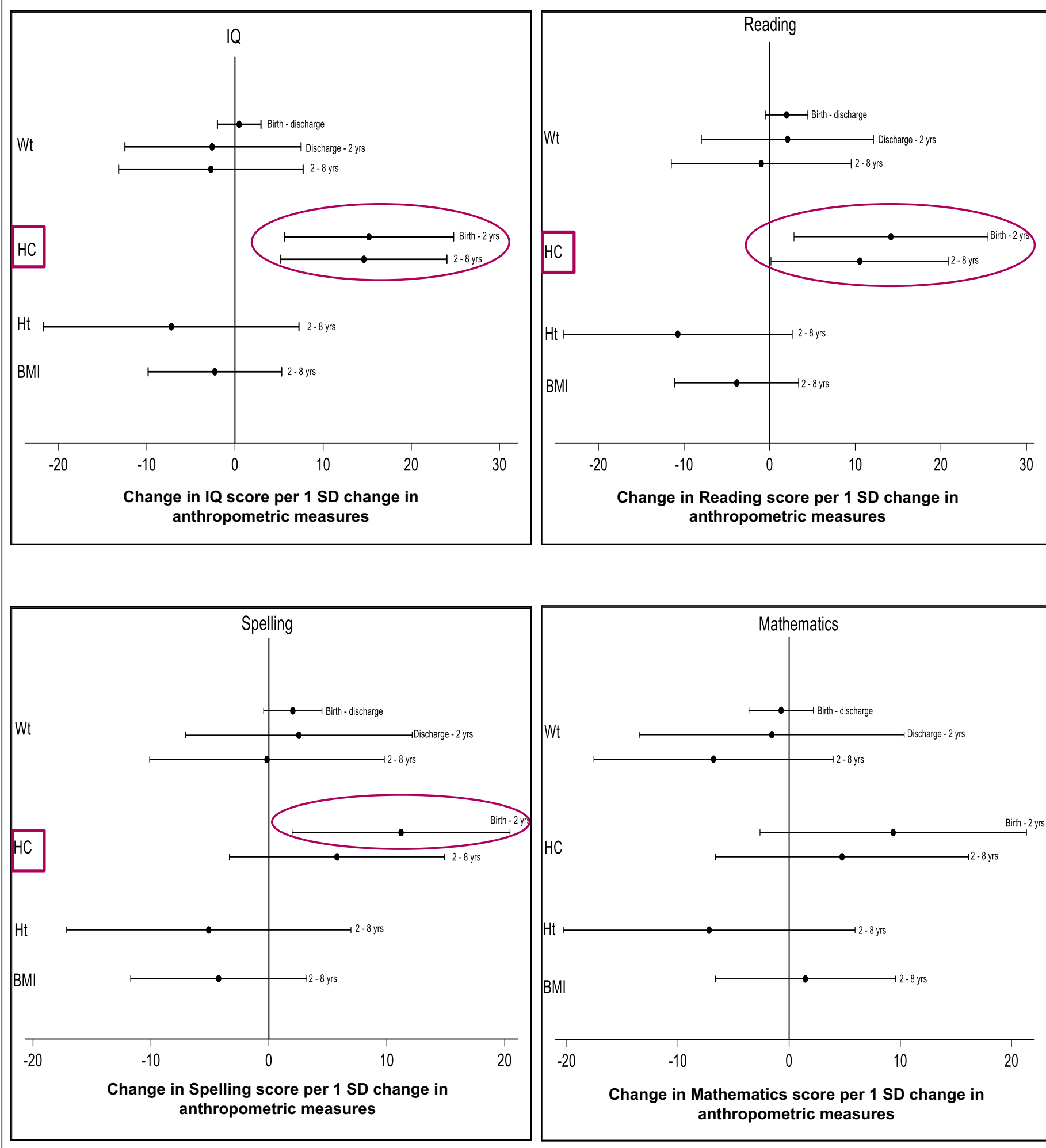

Figure 2 Associations between growth and cognitive and academic outcomes at 8 years

\section{CONCLUSIONS}

A large weight deficit accumulates by the time an EP infant is discharged home from their primary hospitalisation 